\title{
Growing mechanism and change of phase of synthesized CdSe nanoparticles
}

\author{
J. Sarmiento A. ${ }^{1}$, E. Rosendo ${ }^{1}$, A. I. Oliva ${ }^{2}$ and W. De la Cruz ${ }^{3}$ \\ ${ }^{1}$ CIDS-ICUAP, Benemérita Universidad Autónoma de Puebla, Apartado Postal 1651 Puebla, \\ Pue., 72570, México. \\ ${ }^{2}$ Centro de Investigación y de Estudios Avanzados del IPN, Unidad Mérida, Departamento de \\ Física Aplicada, A.P. 73-Cordemex, CP 97310, Mérida Yucatán México. \\ ${ }^{3}$ Centro de Nanociencia y Nanotecnología, Universidad Autónoma de México, Km. 107 \\ Carretera Tijuana-Ensenada CP 22860 Ensenada, B.C., México.
}

\begin{abstract}
Nanostructured cadmium selenide (CdSe) thin films were deposited by evaporation of a CdSe colloidal solution. The colloidal solution containing $\mathrm{Cd}$ and $\mathrm{Se}$ ions was prepared at room temperature. The solution was stirred during $30 \mathrm{~min}$ and cleaned with $\mathrm{HCl}$ and distilled water. The glass substrates were introduced into the colloidal solution and heated at $75^{\circ} \mathrm{C}$ during $2 \mathrm{~h}$ in air environment, the by-products were evaporated and a film on the substrate surface was obtained. The as-deposited films were further annealed in ambient air at $100^{\circ} \mathrm{C}, 200^{\circ} \mathrm{C}$, and $300^{\circ} \mathrm{C}$. Deposited films were characterized by x-ray diffraction (XRD), x-ray photoelectron spectroscopy (XPS) and high-resolution transmission electron microscopy (HRTEM). As-deposited nanoparticles with surface of $\mathrm{CdSe}$ and core of Se $(\mathrm{CdSe} @ \mathrm{Se})$ with mean particle diameter of $\sim 4.5$ nm were observed by HRTEM, after the annealing process, this diameter increased until $\sim 14 \mathrm{~nm}$. XRD results support this results and show a phase combination of cubic and hexagonal CdSe crystalline structures XPS allows showing that crystals are mainly composed of Cd and Se. Based on the experimental results a model of growth for the $\mathrm{CdSe} @ \mathrm{Se}$ structures is proposed and the percent of each crystalline structure with the annealing process is calculated.
\end{abstract}

Keywords: Nanostructured cadmium selenide, Annealing process, Crystal structure, mechanism of growth, HRTEM, XRD. 